\title{
On the Prosperity and Spread of Flower and Bird Painting in the Northern Song Dynasty
}

\author{
Shaoduan Zhang \\ Luoyang Normal University \\ Luoyang, China
}

\begin{abstract}
During the Northern Song Dynasty, flower and bird painting dominated the whole painting world, forming a peak in history. We can see its prosperity from its imperial-court decorative painting, literati painting and folk life painting. Court painters, literati and civil professional painters have made some achievements in the field of flower and bird painting, because the differences of their own life background and cultural accomplishment and other aspects, they made different impact on the spread area and spread form. Under the background of community generally pay attention to flower and bird painting, Northern Song Dynasty flower and bird painting has been a great prosperity, its art level is far beyond the previous generation.
\end{abstract}

Keywords-Northern Song Dynasty; flower and bird painting; court painter

\section{INTRODUCTION}

Chinese flower and bird painting has a long history, its development process accompanied by the whole historical process of traditional Chinese painting from beginning to mature. Flower and bird painting from the ancient stage to Neolithic Age, and then to Wei and Jin Dynasties, finally from an independent branch in Tang Dynasty, and matured in the Five Dynasties. The Northern Song Dynasty flower and bird painting was in the dominant position of the entire painting world in that era, whether it is the imperial-court decorative painting, literati painting or folk flower and bird painting, and no matter in content subject, art form or painting skills., all reached a prosperous period in the history of Chinese painting. The fun of the court, the goodness of the folk people and the literati's unique artistic purpose are the driving forces of the evolution of flower and bird painting. At the same time, it also made certain impact on the spread area and spread form of Northern Song Dynasty flower and bird painting.

\section{THE ORIGIN AND PROSPERITY OF FLOWER AND BIRD PAINTING}

The origin of Chinese flower and bird painting can be traced back to the ancient stage of mankind. After human divorced from the animal kingdom and with initial rational consciousness, they were able to observe and "record" the surrounding things, they paint the figures, animals, plants and astronomical images on the cave stone walls and cliffs. The Flowers and birds, animals with the character images become the object of human description from very early. In Neolithic period, human paint these images on pottery, such as painted pottery painting "Crane fish zax ", is simply the "prototype" of flower and bird painting, the pottery urn painted with six limbs frog pattern, the free use of "brush" even could compare with Qi Baishi's frog painting, Banpo "swimming fish" pattern with mouth open sucking water was exactly the same with pseudonym of Zhu Da's fish painting. Bronze use monster head and face to deter animals in abstract patterns, the stone relief and tile use the auspicious birds the animals arching to the invisible space. Although these animal and plant images are only patterns with only decorative and symbolic, somewhat expressive, but also do not have lyrical, but as a bird image representation and form of foundation function, maybe with some expression function but not with emotion expression function, but as the image representation and formal basis, it is the "ancestor" of flower and bird painting. In Wei Jin Southern and Northern Dynasties, with the rapid development of landscape painting, people gradually realized that in addition to human, all the plants and animals in the world can become the object of lyrical performance. Tang Dynasty's landscape painting has "Song Shi" branch, which directly resulting in the formation of flower and bird painting, which may be an opportunity, not the main cause. In Sui and Tang Dynasties, due to greater social and economic development, after the abundance of food and clothes, watch the strange rocks and grass, appreciate the bird singing and the fragrance of flower have become a spirit enjoy of people after all. Putting this spiritual need into a form of art has become a major trend in the development of painting genre, so many palaces, houses, tombs, temples and screens are decorated with flower and bird paintings. The famous Early Tang Dynasty flower and bird painting painter Xueji created "six screen crane pattern" which was the unique technique at that time. According record from "Tang Dynasty painting recorded" which is written by Zhu Jingxuan, there are more than 20 painters who is good at the flower and bird painting. This way, with the hard work of many artists and literati, the performance of the flower and bird painting is becoming stronger and stronger, and finally became an independent branch in Tang Dynasty, standing together with the landscape and figure painting and become a wonderful work in the traditional Chinese painting garden.

To the Five Dynasties, flower and bird painting developed more vigorous, the best of them include Huang Quan from Later Shu and $\mathrm{Xu} \mathrm{Xi}$ from Southern Tang. Huang Quan 's flower and bird painting has fine composition and bright color, $\mathrm{Xu} \mathrm{Xi}$ 's painting is free from vulgarity, so that it has a saying of wealthy Huang and Wild Xuxi. Huang Quan's only bird and 
bird authentic "Xie Sheng Zhen Qin Tu" has realistic depicting which is amazing. Xu Xi handed down the "Xue Zhu Tu", and self titled of " this bamboo valued million", the future painting masters all admire it so much, they want to copy but no place to start, we can see his high artistic level.

\section{THE PROSPERITY OF NORTHERN SONG DYNASTY'S FLOWER AND BIRD PAINTING}

The Northern Song Dynasty flower and bird painting has a rapid development based on the inheritance of the Tang and the Five Dynasties and reaches a peak in history. We can see its prosperity from its imperial-court decorative painting, literati painting and folk life painting.

\section{A. The Rise of Imperial-Court Decorative Painting}

"Imperial-court decorative painting", generally refers to the court painter's paintings in Song Dynasty Hanlin Art Institute which has the same painting style. From the beginning of the Song Dynasty's quiet peace, delicate and colorful "wealthy Huang" style to Cui Bai's elegant and refine, reflecting the unique characteristics of the Northern Song Dynasty culture.

In the early days of the Northern Song Dynasty, the painters who had worked in the court painting institute created by Later Shu and Southern Tang and the painters from other areas mostly gathered in the capital Bianliang, which accumulated a large number of artistic talent for the future prosperity of Northern Song Dynasty Hanlin Art Institute, laid a solid basis. In the early period of the Northern Song Dynasty, the painting style represented by Huang Quan and his son Huang Jucai became the mainstream of the court flower and bird painting creation. "Xuan He painting spectrum" said: "Huang Quan and Huang Jucai's painting style are the only standard of the Art Institute since the beginning, painters who copy good Huang's painting will be selected in the Institute." Not only it was considered as the model of Hanlin Art institute, it also is the standard weather a painter can enter the Hanlin Art institute, the influence of Huang's painting style has continued nearly a hundred years. Northern Song Guo Ruoxu's "Tu hua jian wen zhi" records, Huang Quan "normally paint all the rare birds and animals, strange flowers and stones in court", in "Xuan He painting spectrum" and other books there are a lot of records of his works, such as Gold basin pigeon, pure white pheasant rabbit, peacock tortoise, peony, deer and so on. From the technical point of view, the Huang style flower and bird painting further improved the "hook fill" performance skills, the Huang painting style is known as the rich and skilled work. Shen Kuo from Song Dynasty has commented "Huang's painting flowers, was good at color use and its very thin pen brush, almost no ink marks, like light dyed, that is called sketch." So that it can be seen that Huang style flower and bird painting is based on observation sketch, use very fine ink lines out of the contours, and then use heavy color to fill in, its style is heavy rich with cautious modeling.

Painting history said: "Since Cui Bai,Cui Que, Wu Yuanyu came out, the painting style suddenly changed." Among them the most famous is Cui Bai who changed the early Song Dynasty flower and bird painting. Cui Bai focused on sketch, he was good at express the flowers and bird spirit in different seasons and natural environments, especially painting the abortive lotus, reed shore, reed river, cold pond, autumn river he has a unique taste. Cui Bai inherited the Song Dynasty "Huang style" painting's fine outline, faithful to the fine carved way to image, and he combined the Huang style and hook dye together to draw the skeletal volume of the image, impose a light color, the image stressed dynamic. His brother Cui Que, his disciples $\mathrm{Wu}$ Yuanyu have similar style with Cui Bai who were the important force to break the "Huang system" dominate the world in early Northern Song Dynasty palace flower and bird painting.

\section{B. Emergence of Literati Flower and Bird Painting}

In the Northern Song Dynasty, there was an amateur painter team which consisted of bureaucratic aristocracy and literati, they also explored and practiced in the field of flower and bird painting and formed a relatively independent system, which was called "scholar painting", later was called "Literati painting".

Representative painters are Wen Tong ,Su Shi and so on, they advocate "Ink play", and gradually deduced with the plum, orchid, bamboo and chrysanthemum "Four gentlemen" painting theme to match "Ink play". They emphasized the painting should pursue "scattered casual light" poetic world, the so-called "poetry in the painting, painting a poem." They advocated improvisation, not rigidly adhere to the shape characterization of the image, asked to achieve "get the meaning and forget the shape" realm. When Wen Tong paints bamboo, he pays attention to in-depth observation and a comprehensive understanding of the natural ecology and the characteristics of bamboo, and creates a whole set of creation method of "bamboo in heart" first and then meaning before the brush and spirit being outside. For the ink bamboo, he often uses light and heavy ink to express the shade of bamboo leaves, which has certain spatial perspective effect. Su Shi's painting has more prominent freehand spirit, he prefers painting of dead wood and bamboo with stone.

\section{The Prosperity of Folk Flower and Bird Painting}

In addition to the court painter and literati, there is a considerable number of professional painters in folk which is also a painting power can not be underestimated. Folk flower and bird paintings exist all the time and everywhere. Clothing patterns in this period gradually began to get rid of the dignified pure decorative function in Sui and Tang dynasty and tend to sketch and decoration combined together, sketch-type pattern "color flower" was very popular. All the peony, plum, lotus, camellia, bamboo, Yinan, papaya, pine needles and Ying Feng, peacocks, gulls, cordyceps sinensis and other clothing patterns were within the sketch range. In ceramic surface painting, the Song Dynasty Cizhou pottery painting type mainly was flower and bird painting, because the emperor Zhao Ji liked the fine and neat flower and bird painting, resulting in Cizhou kiln ceramic flower painting works were deeply affected, porcelain performance was also pursuit of fine neat painting method.

\section{THE SPREAd AREA AND SPREAD Form OF FlOWER AND BIRD PAINTING}

Court painters, literati and civil professional painters have made some achievements in the field of flower and bird 
painting, because the differences of their own life background and cultural accomplishment and other aspects, they made different impact on the spread area and spread form.

\section{A. The Spread Area,Form and Reason of Imperial-Court Decorative Painting}

Northern Song Dynasty Hanlin Art Institute was a specialized institute which only served for the court emperor and dignitaries, painting artists' artistic creation also mainly serve for the royal court. On one hand is to maintain the political rule of feudal rulers, exert painting's education function, on the other hand is to help rulers to present a false appearance of peace and prosperity, to meet the endless enjoyment of the upper social needs, so the spread area of imperial-court decorative painting is mainly between the court and the royal family members. In the court, those animals specifically designed for the enjoyment are more popular, flower and bird painting gradually becomes an important subject. Painting style is also from the vigorous and broad gradually become slender, restrained, flower and bird is the best performance theme for this art style, so the flower and bird paintings of this time more loved by the Royal.

The imperial-court decorative flower and bird painting is first used for the court emperor, dignitaries' leisurely enjoyment and mutual observation between painting artists, also sometimes as gifts presented to each other. At the same time, the art institute is also responsible for the search of all kinds of paintings and ancestral handwriting books for the royal family to collect and watch, the history book recorded "The Five Dynasties paintings and all the collection of paintings are in the royal government". Northern Song Su Yijian has also been sent by the emperor to Jiangnan to search ancient paintings, he found thousands of volumes and he also received a hundred rolls of reward because of the merits of the search. As the interior decoration of palace and the temple, many famous palace frescoes, official screen wall paintings in the Northern Song Dynasty's are the artwork of institute painters in order to add brilliant colors. Most of the emperors of Song Dynasty love literature calligraphy and painting, and sometimes the emperor also ordered the painter to paint for him and add his emperor seal to reward meritorious minister. Song Huizong is the emperor who has deep knowledge of flower and bird painting, especially the achievements in the fan painting, he often made his own painting and calligraphy fan and sent to the ministers. Under his influence, the flowers and bird fan painting was very popular then. In addition, the painter paint for other country's emperor has also become an important task of the country's foreign affairs, which shows the government's emphasis on painting.

\section{B. The Spread Area,Form And Reason of Literati and cholar- Bureaucrat Flower and Bird Painting}

Literati's enthusiasm of politics and praised the integrity have impact that can not be underestimated for the painting. The reason why literati paintings which do not focus on image similarity get popular in Song Dynasty is of course related to the depression caused by the failure of the political life, because the "water the gloom in the chest" has become a new creative tendency, so that "scholar painting" formed an aesthetic taste which not judged by the image and color but emotion expression became the main factor of their painting aesthetics, at the same time, longing for noble personality, unyielding symbolic painting. So their flower and bird painting was generally used for self-appreciation, or as a gift to good friends.

At that time, the collection, taste and creation of paintings became a common practice in the upper class literati, which first manifested in their spare no effort to collect and seeking paintings. "Xuan He painting spectrum" Volume 20 also recorded Zhao Dainian "born and grow from palace, lived in royal and wealthy family, but he liked to read history and calligraphy, especially good at painting, he liked to collect famous paintings since Jin and Song Dynasty". In order to better preserve and collect paintings, a lot of qualified scholar literati in Song Dynasty also built a pavilion to store paintings. Such as Wen Tong had built a Mo Jun Tang in his house, where is especially used to collect and hang the ancient calligraphy and paintings on the wall for daily appreciation. $\mathrm{Su}$ Shi wrote "Baohuitang Ji" to praise him "Although he is from royal family but he likes to study etiquette, learn knowledge and read poetry and books, he often compete with poor literati. $\mathrm{He}$ lives in simple decorated house and stay away from entertainment, he likes calligraphy and painting. So he builds Baohuitang at the east of his house in order to store all of his collections." Also there is a poem which could be proved some poems. "From which we could see how obsessed people was with art at that time. Not only private collection, all levels of bureaucratic office in Song Dynasty also arranged to display a lot of paintings, which is in order to create a good working environment, showing the elegant and refined artistic taste of that group, such as Lu You wrote in the poem "Li Hua": "Zhengxi Mufu Jianchadi, Yifu Bianluan Huazhezhi." And he noted after it with: "There is Bian Luan's pear blossom painting on the screen of Xuansi Jingzhen Tang." Here the painting screen was just like the finishing touch to contrast the elegant cultural atmosphere in that military government.

\section{The Spread Area,Form and Reason of Folk Flower and Bird Painting}

The reunification of the Northern Song Dynasty eliminated the divisions and segregation caused by the feudal separatism. During a period of time, the society maintained a relatively stable situation, the rapid development of the commercial handicraft industry, the urban layout broke the strict boundaries of Fang and Shi, and appeared the unprecedented prosperity. Northern Song Dynasty's Bian Liang and other cities have prosperous business, in addition to the aristocrats, there are also a large number of businessmen, craftsmen and civic strata, the city's cultural life is unprecedentedly active, the demand for painting has increased significantly, and the service object of painting has also been expanded. Song Dynasty's painting enter the ranks of the handicraft industry, and establish a more closely link with more people. A group of superb professional painters put their works in the market and sold as a commodity, Bianjing and Lin'an all have paper painting industry. Bianjing Grand Xiangguo Temple held 5 temple fairs a month, all the things sold on the fair which include stores which sold books and paintings. Citizens who have to hold event of festive banquet, they could rent the required screen, book, painting and calligraphy. The sale of calligraphy and painting fans has 
become a unique industry in three hundred and sixty industries, at that time, from the emperor to minister to the citizen, the atmosphere of buy, sell, play and collect fans are very popular. In Dong Jing of Song Dynasty, embroidery is also very popular, ordinary people use it to decorate wedding and funeral clothes. Patterns were mainly with flower and grass sketch, the collection of four seasons open flowers, such as peony, Malan, Begonia, rose, camellia, peach, pear, peony, chrysanthemum, etc., composed of lace pattern. In addition to these, flowers and birds painting decorations in pavilions were also very common.

\section{CONCLUSION}

People of Song Dynasty have showed a great passion for the creation of flower and bird painting, they gave a high degree of attention to flower and bird painting. The establishment of the Northern Song Dynasty painting institute provided a very favorable condition for the creation of flower and bird painting, around imperial-court decorative painting, higher sponsorship and collection circle formed by royal and aristocratic competing to enhance the taste and level of flower and bird painting, this atmosphere is beyond times, beyond society, beyond utilitarian. From the late Northern Song Dynasty to Southern Song Dynasty, it was the first great turning point in the history of Chinese painting. First is the emergence of "literati painting", followed by "imperial-court decorative" praise of fine sketch and line in painting techniques, but the poetic painting phenomenon was still affected by "literati painting". Although the literati painting in the Song Dynasty can not control the painting world, also not the mainstream of Song Dynasty painting, but as the development period of literati painting, it kept develop itself during the process of struggle and connect with the imperial-court decorative painting. The prosperity of the civilian culture in Song Dynasty and the improvement of the status of common people made an obvious change for painting, that is, painting from the court to the folk, from elite to common people. With the development of the city and commercial prosperity, painting from serve the court and temples to become a commodity, in people's lives, flower and bird painting decorations are rich and colorful. Under the background of community generally pay attention to flower and bird painting, Northern Song Dynasty flower and bird painting has been a great prosperity, its art level is far beyond the previous generation.

\section{REFERENCES}

[1] Chen Yan. The history of Chinese aesthetic culture. Jinan. Shandong Pictorial Publishing Company in 2007

[2] Yue Ren translation "Xuan He painting spectrum" Hunan Art Publishing Company 1999.3

[3] Hong Zaixin. Chinese Art History. Hangzhou: China Academy of Fine Arts Publishing Company. 2000

[4] Jiang Weigang, "Fan painting techniques", Liaoning Fine Arts Publishing Company, July 2002. 